\title{
O surto de Zika vírus: produção científica após Declaração de Emergência Nacional em Saúde Pública
}

The outbreak of Zika virus: scientific production after National Emergency Declaration in Public Health

El surto de Zika virus: producción científica tras Declaración de Emergencia Nacional en Salud Pública

\author{
Paula de Souza Silva FREITAS ${ }^{1}$
}

Elda Coelho de Azevedo BUSSINGER ${ }^{2}$

Larissa Carolina Xavier LACERDA ${ }^{3}$

Gabriella Barreto SOARES ${ }^{4}$

Ethel Leonor Noia MACIEL ${ }^{\mathbf{5}}$

${ }^{1}$ Doutoranda do Programa de Saúde Coletiva da Universidade Federal do Espírito Santo, UFES, 29043-900, Vitória -ES, Brasil. ${ }^{2}$ Docente da Faculdade de Direito de Vitória, FDV, 29056-295, Vitória -ES, Brasil

${ }^{3}$ Graduanda em enfermagem na Universidade Federal do Espírito Santo, UFES, Campus São Mateus, 29932-900, ES, Brasil

${ }^{4}$ Pós-doutoranda do Programa de Saúde Coletiva da Universidade Federal do Espírito Santo, UFES, 29043-900, Vitória -ES, Brasil

${ }^{5}$ Docente do Programa de Saúde Coletiva da Universidade Federal do Espírito Santo, UFES, 29043-900, Vitória-ES, Brasil

\section{Resumo}

Introdução: Em 2015 houve um aumento dramático da infecção por Zika vírus nas Américas, sendo o Brasil o país mais afetado, com estimativa média de 1,5 milhão de casos de infecção pelo vírus, isso levou ao Ministério da Saúde declarar situação de emergência nacional. Objetivo: Identificar o que foi produzido no campo científico sobre a infecção do Zika vírus após a declaração de emergência em saúde pública de importância nacional. Método: Trata-se de uma revisão integrativa da literatura, com artigos publicados após a declaração de emergência nacional em saúde pública, nas bases de dados eletrônicas disponíveis na Biblioteca Regional de Medicina. Os descritores utilizados foram Zika vírus e Infecção pelo Zika, resultando em 428 publicações, mas com aplicação dos critérios de inclusão reduziram-se para 40 estudos. Desse total, foram eleitos 7 artigos para serem utilizados na revisão integrativa. Resultados: Dos artigos revisados todos estavam publicados na língua inglesa, em revistas relacionadas à saúde pública e com alto fator de impacto. Quanto ao ano de publicação todos foram publicados em 2016. No que diz respeito à nacionalidade dos artigos, constatou-se que três estudos foram realizados na Polinésia Francesa, dois no Brasil, um na Colômbia e um na Eslovênia. Em relação ao tipo de delineamento de pesquisa, foram evidenciados três estudos eram ensaios clínicos, dois retrospectivos, um caso-controle e um experimental. Conclusão: Observa-se que a produção por artigos científicos após a declaração de emergência sanitária, resultou no desenvolvimento estável do interesse científico no vírus Zika e em crescimento considerável no número de publicações com o tema.

Descritores: Zika Vírus; Infecção pelo Zika Vírus; Declaração de Estado de Emergência em Desastres; Saúde Pública; Microcefalia; Infecções por Arbovírus.

\section{Abstract}

Background: In 2015, there was a dramatic increase in Zika virus infection in the Americas, Brazil being the country most affected, with an average estimate of 1.5 million cases of virus infection. This led the Ministry of Health to declare a national emergency situation Objective: To identify what was produced in the scientific field on the infection of the Zika virus after the declaration of public health emergency of national importance. Method: This is an integrative review of the literature, with articles published after the declaration of national emergency in public health, in the electronic databases available at the Regional Library of Medicine. The descriptors used were Zika virus and Infection by Zika, resulting in 428 publications, but with application of the inclusion criteria were reduced to 40 studies. Of this total, 7 articles were chosen to be used in the integrative review. Results: All articles were published in the English language, in journals related to public health and with a high impact factor. As for the year of publication, all were published in 2016. Regarding the nationality of the articles, it was found that three studies were conducted in French Polynesia, two in Brazil, one in Colombia and one in Slovenia. Regarding the type of research design, three studies were clinical studies, two retrospective, one case-control and one experimental. Conclusion: It is observed that the production by scientific articles after the sanitary emergency declaration, resulted in the stable development of the scientific interest in the Zika virus and in considerable growth in the number of publications with the theme. Descriptors: Zika Vírus; Zika Vírus Infection; Declaration of Emergency; Public Health; Microcephaly; Arbovirus Infections.

\section{Resumen}

Introducción: En el año 2015 hubo un aumento dramático de la infección por Zika virus en las Américas, siendo Brasil el país más afectado, con una estimación promedio de 1,5 millones de casos de infección por el virus, esto llevó al Ministerio de Salud declarar situación de emergencia nacional . Objetivo: Identificar lo que fue producido en el campo científico sobre la infección del Zika virus después de la declaración de emergencia en salud pública de importancia nacional. Método: Se trata de una revisión integrativa de la literatura, con artículos publicados después de la declaración de emergencia nacional en salud pública, en las bases de datos electrónicas disponibles en la Biblioteca Regional de Medicina. Los descriptores utilizados fueron Zika virus e Infección por Zika, resultando en 428 publicaciones, pero con aplicación de los criterios de inclusión se redujeron a 40 estudios. De ese total, fueron elegidos 7 artículos para ser utilizados en la revisión integrativa. Resultados: De los artículos revisados todos estaban publicados en la lengua inglesa, en revistas relacionadas a la salud pública y con alto factor de impacto. En cuanto a la nacionalidad de los artículos, se constató que tres estudios se realizaron en la Polinesia Francesa, dos en Brasil, uno en Colombia y uno en Eslovenia. En cuanto al tipo de delineamiento de investigación, se evidenciaron tres estudios eran ensayos clínicos, dos retrospectivos, un caso-control y un experimental. Conclusión: Se observa que la producción por artículos científicos tras la declaración de emergencia sanitaria, resultó en el desarrollo estable del interés científico en el virus Zika y en crecimiento considerable en el número de publicaciones con el tema.

Descriptores: Vírus Zika; Infección por el Virus Zika; Declaración de Emergencia; Salud Pública; Microcefalia; Infecciones por Arbovirus.

\section{INTRODUÇÃO}

O Zika vírus foi descoberto em 1947, no macaco asiático de nome Rhesus 766, na floresta Zika, em Uganda. A primeira descrição formal foi publicada em 1954, por Francis N. Macnamara, em meio a um surto de icterícia em região nigeriana. $\mathrm{O}$ vírus possui como vetor o mosquito Aedes Aegypti, porém nessa época, não foi considerado com potencial de gravidade nos seres humanos, tendo sua sintomatologia considerada leve, incluindo sintomas como dor de cabeça leve e febre baixa ${ }^{1}$

O primeiro surto de Zika vírus ocorreu em 2007, quando foi constatada pela primeira vez a presença da doença fora de solo africano ou asiático. O cenário era a ilha Yap, no oeste do Pacífico, contudo não houve conhecimento de casos graves descritos na literatura ${ }^{2}$. Já ano de 2013, o Zika vírus surge em uma das principais ilhas da Polinésia Francesa: o Taiti. Era o segundo surto no mundo, mas dessa 
vez com inúmeros casos de pacientes com diferentes graus de paralisia, que afirmavam ter apresentado sintomas do Zika nos dias anteriores. Os casos de paralisia foram reconhecidos como a síndrome de Guillain-Barré . $^{3}$

No início de 2015, pouco depois da realização da Copa do Mundo de Futebol, o Brasil entra para a lista dos países visitados pelo vírus. Sugere-se sua chegada ao país durante a Copa, ou até mesmo, durante o Campeonato Mundial de Canoagem ocorrido logo em seguida. O vírus foi diagnosticado primeiramente na região Nordeste do Brasil, principalmente em bairros pobres e periféricos, onde as pessoas vivem em locais sem saneamento básico, favorecendo a proliferação do vetor Aedes Aegypti ${ }^{4-5}$.

Em meio ao surto de Zika, os jornais brasileiros começaram a noticiar, também, um índice altamente elevado de casos notificados de microcefalia em crianças nascidas vivas na região Nordeste $^{1}$. Junto à essas notificações, diversas especulações nas mídias sociais ligando a microcefalia à uma reação vacinal e ao uso de agrotóxicos gerou temor e medo entre a população. A vigilância em saúde do Nordeste e a Dr. ${ }^{\text {a }}$ Adriana Melo (médica obstetra paraibana vinculada ao Sistema Único de Saúde) já sinalizavam a causalidade entre o Zika vírus e a microcefalia fetal. Contudo, houve demora, ceticismo e desconfiança em relação aos dados apresentados. Posteriormente, os médicos de beira leito, trabalhadores do Sistema Único de Saúde (SUS) e desconhecidos na comunidade acadêmica, tornaram-se cientistas reconhecidos no cenário mundial ${ }^{2}$.

Somente após a chegada de pesquisadores internacionais ao Recife e as primeiras publicações científicas terem confirmado a causalidade é que ficou evidente a forte relação temporal entre o surto do vírus Zika e o aumento da prevalência de microcefalia no Brasil, além do fato dos casos de crianças microcefálicas terem tido, em sua maioria, origem nos estados com transmissão do vírus, confirmada laboratorialmente ${ }^{6}$.

Nesse cenário desfavorável, diante da repercussão mundial da causalidade da microcefalia fetal, e a magnitude do problema, devido as sérias consequências para as crianças, além do número crescente de casos e das evidências já disponíveis, o Ministério da Saúde, em 15 de novembro de 2015 declarou estado de emergência nacional de saúde, usando pela primeira vez o mecanismo criado em 2011, a Portaria $\mathrm{n}^{\circ} 2.952$, de 14 de dezembro de 2011 e por meio dela, recursos financeiros do MS foram repassados para o combate à emergência do surto de Zika vírus ${ }^{7}$.

Diante da necessidade de aprofundar e comprovar a associação do Zika vírus com a microcefalia fetal, bem como entender o comportamento do surto no território brasileiro, diversas instituições de pesquisas nacionais e internacionais iniciaram suas investigações. A comunidade acadêmica, diante do quadro de decreto de emergência sanitária, recebeu do governo americano e do Ministério da Saúde uma série de editais de incentivo à pesquisa, para encontrar as respostas para o combate ao Zika vírus. Com isso, faz-se necessário identificar as evidências disponíveis na literatura científica sobre a infecção do Zika vírus após a declaração de emergência em saúde pública de importância nacional.

\section{MATERIAL E MÉTODO}

Trata-se de revisão integrativa da literatura sobre a infecção do Zika vírus após a declaração de emergência nacional em saúde pública, caracterizada por selecionar publicações que possibilitem a síntese do estado do conhecimento de determinado assunto e questões que precisam ser verificadas com novos estudos. A revisão integrativa é o instrumento da Prática Baseada em Evidências (PBE), que propicia a seleção e a análise da informação produzida sobre uma temática em investigação. Consiste em uma técnica de pesquisa com rigor metodológico que traz fiabilidade e densidade às conclusões da revisão ${ }^{8}$. A revisão integrativa da literatura compõe as seguintes etapas, a saber: estabelecimento da questão norteadora; estabelecimento de critérios de inclusão e exclusão de artigos; seleção e obtenção dos artigos; avaliação dos estudos pré-selecionados; discussão dos resultados e consolidação final.

Dessa forma, elaborou-se a seguinte questão norteadora: "O que foi produzido no campo científico sobre a infecção do Zika vírus após a declaração de emergência em saúde pública de importância nacional?".

Em seguida, realizou-se uma busca pelos artigos em outubro de 2016, nas bases de dados eletrônicas disponíveis na Biblioteca Regional de Medicina (BIREME), especificamente na Literatura Latino-Americana e do Caribe em Ciências da Saúde (LILACS), Literatura Internacional em Ciências da Saúde (MEDLINE), Base de Dados em Enfermagem (BDEnf) e Scientific Eletronic Library Online (SciELO). Foram utilizadas para a busca as palavras-chave indexadas no Descritores em Ciências da Saúde (DeCS): Zika vírus e Infecção pelo Zika, cruzadas em combinação com o operador booleano AND.

Os critérios de inclusão estabelecidos para a seleção foram: ser artigo original; ter disponibilidade eletrônica na forma de texto completo; ter sido publicado após a declaração de emergência nacional em saúde pública (11 de novembro de 2015) e estar nos idiomas português, inglês ou espanhol. Os critérios de exclusão incluíam: estudos que não respondiam à questão norteadora; artigos que se encontravam repetidos em uma ou mais bases de dados; estudos em forma de revisões de literatura, comunicações, cartas, notas editoriais, artigos de opinião, teses e dissertações.

A busca bibliográfica resultou inicialmente em 428 publicações que poderiam compor a amostra. Após leitura do título e resumo, aplicação dos critérios de inclusão e exclusão esse número foi reduzido para 40 estudos. Por meio deste conjunto, foi realizada uma análise minuciosa dos artigos na íntegra e foram eleitos 7 artigos, de acordo com afinidade e aproximação do objetivo deste estudo, constituindo nossa amostra final. Cabe ressaltar que foi realizada uma revisão por pares como forma de assegurar mais rigor e credibilidade na seleção dos artigos. Tal processo é representado através da Figura 1.

\section{RESULTADOS}

$\mathrm{Na}$ presente revisão integrativa foram analisados sete estudos que atenderam aos critérios de inclusão e que serão apresentados a seguir. Todos os artigos encontrados estavam publicados na língua inglesa; as revistas em sua maioria eram relacionadas à saúde pública e revistas com alto fator de impacto. Quanto ao ano de publicação todos foram publicados em 2016. No que diz respeito à nacionalidade dos artigos, três estudos foram realizados na Polinésia Francesa, dois no Brasil, um na Colômbia e um na Eslovênia. Em relação ao tipo de delineamento de pesquisa, foram evidenciados três estudos eram ensaios clínicos, dois retrospectivos, um caso-controle e um experimental. 


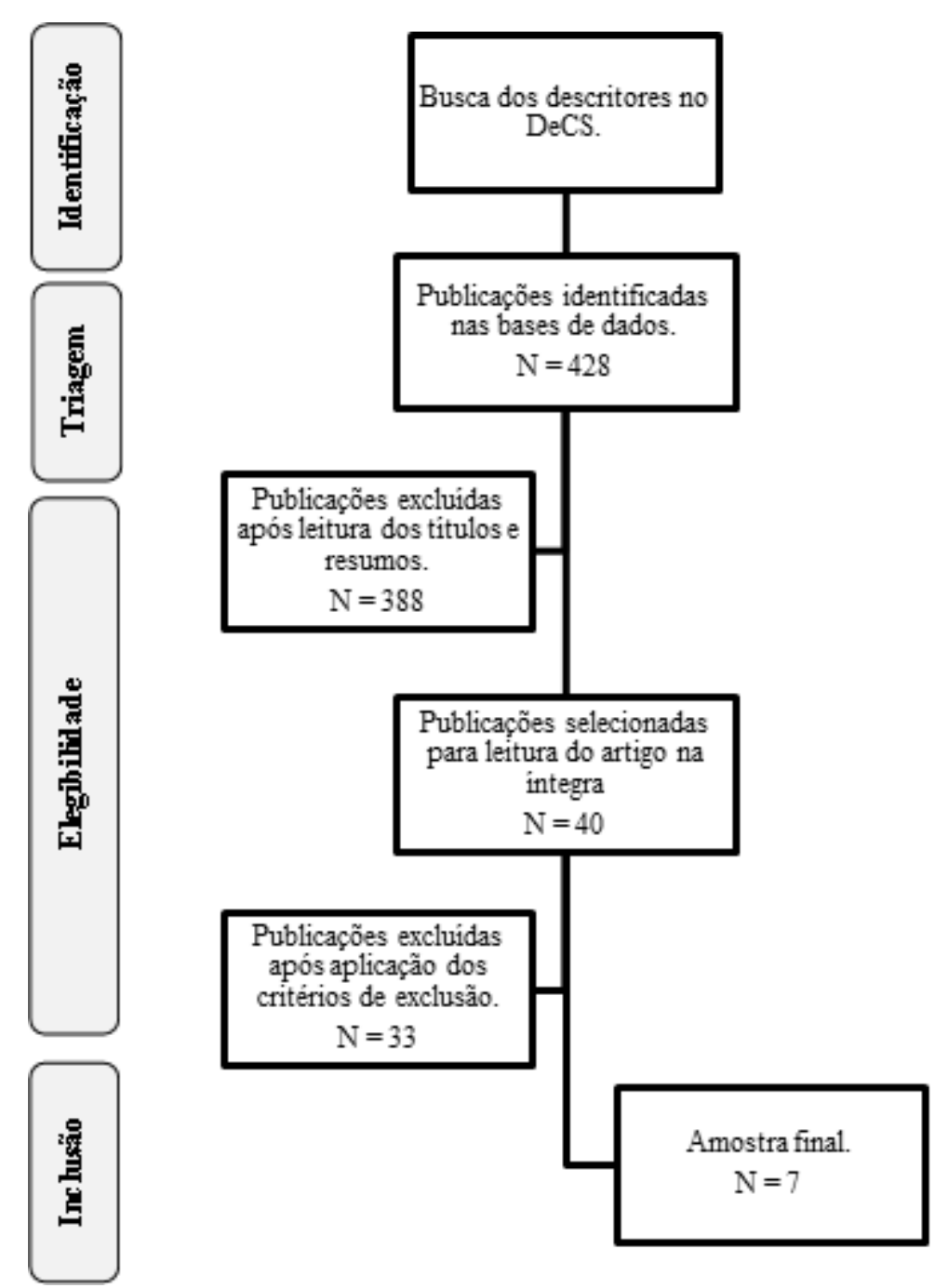

Figura 1: Fluxograma descritor do processo de seleção dos estudos para a revisão.

A Tabela 1 apresenta uma síntese dos artigos eleitos para a revisão, com quadro sinóptico especialmente construído para esse fim, que contemplou os seguintes aspectos considerados pertinentes: título do artigo; revista da publicação e ano; autores; resultados; recomendações/ conclusões.

\section{DISCUSSÃO}

A onda de produção científica acerca do vírus Zika, iniciada após a declaração de emergência em saúde pública, contou desde publicações de grandes centros de pesquisa à publicações de cientistas locais, clínicos e professores relatando as suas descobertas. Além disso, estimulou a realização de estudos retrospectivos a fim de identificar relações entre a infecção do vírus Zika na ilha Yap, Polinésia Francesa e no Brasil ${ }^{2}$.

A Polinésia Francesa tem experimentado, desde 2013, um grande surto de infecções pelo vírus Zika, com aproximadamente $11 \%$ da população acometida, permitindo assim, quantificar e caracterizar a associação entre a infecção pelo vírus na gravidez e a microcefalia ${ }^{9}$. No entanto, provavelmente o número de infecções em recémnascidos foi subestimado pela falta de diagnóstico e acompanhamento. Dessa forma, o surto de infecção por Zika vírus brasileiro de 2015 foi o primeiro a ter uma associação entre este vírus e a grave complicação dos recém-nascidos com microcefalia ${ }^{10}$.

Outra forte evidência da transmissão vertical do vírus seria o achado do Zika no líquido amniótico de dois fetos com microcefalia. O cérebro e os olhos são definidos como principais alvos, tendo em vista o sistema nervoso central gravemente afetado e o retardo do crescimento intrauterino ${ }^{11}$.

Dentre as complicações apresentadas pela microcefalia, um relevante achado foi anormalidades oculares em nascidos entre maio e dezembro de 2015, no Brasil, incluindo alterações maculares (depósito pigmentar grosseiro e/ou atrofia coriorretiniana) e no nervo óptico (hipoplasia do disco, palidez e/ou aumento da escavação papilar). Demonstra-se assim, a necessidade de estudos futuros, a fim de avaliar a importância destas alterações visuais $^{10}$.

Tabela 1. Síntese dos artigos incluídos na revisão integrativa de acordo com as descrições do título, revista, ano de publicação, autores, resultados principais e conclusões

\begin{tabular}{|c|c|c|c|c|}
\hline Título do artigo & $\begin{array}{l}\text { Revista } \\
\text { Ano }\end{array}$ & Autor & Resultados & $\begin{array}{l}\text { Recomendações } \\
\text { Conclusões }\end{array}$ \\
\hline $\begin{array}{l}\text { Guillain-Barré } \\
\text { Syndrome } \\
\text { outbreak } \\
\text { associated with } \\
\text { Zika virus } \\
\text { infection in } \\
\text { French Polynesia: } \\
\text { a case-control } \\
\text { study } \\
\end{array}$ & $\begin{array}{l}\text { The } \\
\text { Lancet } \\
2016\end{array}$ & $\begin{array}{c}\text { Cao- } \\
\text { Lormeau } \\
\text { et al }^{3}\end{array}$ & $\begin{array}{c}42 \text { pacientes foram } \\
\text { diagnosticados com } \\
\text { síndrome de Guillain- } \\
\text { Barré durante o perído } \\
\text { do estudo. Destes, } 41 \\
\text { pacientes apresentavam } \\
\text { IgM ou IgG anti-Zika e } \\
\text { todos tinham anticorpos } \\
\text { neutralizantes contra } \\
\text { Zika. } \\
\end{array}$ & $\begin{array}{l}\text { Este é o primeiro estudo que } \\
\text { fornece evidências de que a } \\
\text { síndrome de Guillain-Barré } \\
\text { pode ser causada pelo vírus } \\
\text { Zika. Com o vírus se } \\
\text { dispersando pelas Américas, } \\
\text { é necessário que os países em } \\
\text { risso se preparem para } \\
\text { tratamento intensivo dos } \\
\text { pacientes com a síndrome. }\end{array}$ \\
\hline $\begin{array}{l}\text { Association } \\
\text { between Zika } \\
\text { virus and } \\
\text { microcephaly in } \\
\text { French Polynesia, } \\
\text { 2013-15: a } \\
\text { retrospective } \\
\text { study } \\
\end{array}$ & $\begin{array}{l}\text { The } \\
\text { Lancet } \\
2016\end{array}$ & $\begin{array}{l}\text { Cauchemez } \\
\text { et al }^{9}\end{array}$ & $\begin{array}{l}\text { A prevalência de } \\
\text { microcefalia foi de dois } \\
\text { casos por } 10.000 \text { recém- } \\
\text { nascidos e o risco de } \\
\text { microcefalalia associado à } \\
\text { infeçąo do Zika vírus foi } \\
\text { de } 95 \text { casos por } 10.000 \\
\text { mulheres infectadas no } \\
\text { primeiro trimestre. }\end{array}$ & $\begin{array}{l}\text { Os resultados fornecem uma } \\
\text { estimativa quantitativa do } \\
\text { risco de microcefalia em } \\
\text { fetos e neonatos, cujas mães } \\
\text { estão infectadas com o vírus } \\
\text { Zika. }\end{array}$ \\
\hline $\begin{array}{l}\text { Ophthalmological } \\
\text { findings in infants } \\
\text { with microcephaly } \\
\text { and presumable } \\
\text { intra-uterus Zika } \\
\text { virus infection }\end{array}$ & $\begin{array}{l}\text { Arquivos } \\
\text { Brasileir } \\
\text { os de } \\
\text { Oftalmol } \\
\text { ogia2016 }\end{array}$ & $\begin{array}{l}\text { Ventura } \\
\text { et al }{ }^{10}\end{array}$ & $\begin{array}{l}\text { 70\% das mães referiram } \\
\text { mal-estar, erupcãao } \\
\text { cutânea e artralgia } \\
\text { durante a gravidez, } \\
\text { tendo } 85 \% \text { apresentado } \\
\text { no } 1^{\circ} \text { trimestre. Não } \\
\text { foram identificadas } \\
\text { anormalidades } \\
\text { oftalmológicas nas mães } \\
\text { e elas não relataram } \\
\text { sintomas oculares } \\
\text { durante a gravidez. Os } \\
\text { achados oculares } \\
\text { incluíram alteraçōes } \\
\text { maculares em } 75 \% \text { dos } \\
\text { olhos e anormalidades } \\
\text { do nervo óptico em } 45 \% \\
\text { dos olhos. }\end{array}$ & $\begin{array}{l}\text { Os pacientes apresentaram } \\
\text { segmento anterior normal e } \\
\text { anormalidades importantes } \\
\text { do nervo macular e do nervo } \\
\text { optico. Outros estudos } \\
\text { avaliarão o significado visual } \\
\text { dessas alterações. }\end{array}$ \\
\hline $\begin{array}{l}\text { Zika virus } \\
\text { associated with } \\
\text { microcephaly }\end{array}$ & $\begin{array}{l}\text { The New } \\
\text { England } \\
\text { Journal } \\
\text { of } \\
\text { Medicine } \\
2016\end{array}$ & $\begin{array}{l}\text { Mlakar } \\
\text { et al }^{11}\end{array}$ & 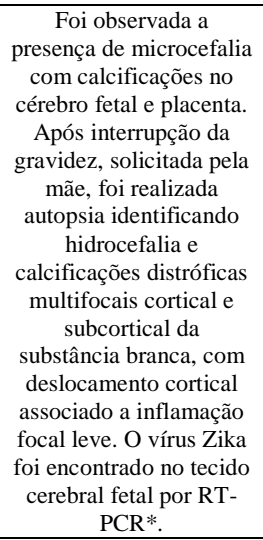 & $\begin{array}{l}\text { Pesquisas adicionais são } \\
\text { necessárias para entender } \\
\text { melhor as possíveis } \\
\text { implicaşoes dessas } \\
\text { observaços. É provável que } \\
\text { a rápida disseminação do } \\
\text { vírus Zika em todo o mundo } \\
\text { seja um forte ímpeto para a } \\
\text { pesquisa sobre as } \\
\text { propriedades biológicas } \\
\text { deste. }\end{array}$ \\
\hline $\begin{array}{l}\text { The Brazilian Zika } \\
\text { virus strain causes } \\
\text { birth defects in } \\
\text { experimental } \\
\text { models }\end{array}$ & $\begin{array}{l}\text { Nature } \\
2016\end{array}$ & $\begin{array}{l}\text { Cugola } \\
\text { et al }^{12}\end{array}$ & $\begin{array}{l}\text { O vírus Zika infecta } \\
\text { fetos, causando restriç̃oo } \\
\text { de crescimento intra- } \\
\text { uterino, incluindo sinais } \\
\text { de microcefalia em } \\
\text { camundongos. Além } \\
\text { disso, o vírus infecta } \\
\text { células progenitoras } \\
\text { corticais humanas, } \\
\text { levando a um aumento } \\
\text { da morte celular. }\end{array}$ & $\begin{array}{c}\text { Os dados reforçam o } \\
\text { crescente corpo de } \\
\text { evidênnias que ligam o surto } \\
\text { de vírus Zika ao alarmante } \\
\text { número de casos de } \\
\text { malformaçốs encefálicas } \\
\text { congênitas. O modelo pode } \\
\text { ser usado para determinar a } \\
\text { eficiênniaia de abordagens } \\
\text { terapêuticas para neutralizar } \\
\text { o impacto nocivo do vírus } \\
\text { Zika no } \\
\text { neurodesenvolvimento } \\
\text { humano. }\end{array}$ \\
\hline $\begin{array}{c}\text { Guillain-Barré } \\
\text { Syndrome (42 } \\
\text { cases) occurring } \\
\text { during a Zika } \\
\text { virus outbreak in } \\
\text { French Polynesia }\end{array}$ & $\begin{array}{c}\text { Medicine } \\
-- \\
\text { Editorial } \\
\text { Elsevier } \\
2016\end{array}$ & $\begin{array}{l}\text { Watrin } \\
\text { et al }{ }^{13}\end{array}$ & $\begin{array}{c}\text { A maioria dos pacientes } \\
\text { eram polinésios nativos, } \\
\text { exceto 2, com } \\
\text { predominância do sexo } \\
\text { masculino. . } \\
\text { admissão, } 38 \% \text { não } \\
\text { foram capazes de } \\
\text { caminhar sem auja, } \\
24 \% \text { tiveram problemas } \\
\text { de deglutição, } 74 \% \\
\text { apresentaram fragilidade } \\
\text { nos membros eos } \\
\text { reflexos tendinosos } \\
\text { profundos foram } \\
\text { diminuídos ou não } \\
\text { encontrados na maioria } \\
\text { dos pacientes. }\end{array}$ & $\begin{array}{l}\text { Esta epidemia levanta várias } \\
\text { questões, tais como a } \\
\text { existência potencial de } \\
\text { interaçôes entre o vírus Zika } \\
\text { e o sistema antígeno } \\
\text { leucocitário humano } \\
\text { polinésio e/ou as } \\
\text { consequências de vários } \\
\text { eventos da recombinação } \\
\text { deste vírus. Esta situação } \\
\text { exige maior vigilância, } \\
\text { especialmente nos países } \\
\text { onde o mosquito aedes } \\
\text { encontra-se presente. }\end{array}$ \\
\hline $\begin{array}{l}\text { Guillain-Barré } \\
\text { Syndrome } \\
\text { associated with } \\
\text { Zika virus } \\
\text { infection in } \\
\text { Colombia }\end{array}$ & $\begin{array}{l}\text { The New } \\
\text { England } \\
\text { Journal } \\
\text { of } \\
\text { Medicine } \\
2016\end{array}$ & $\begin{array}{l}\text { Parra } \\
\text { et al }^{14}\end{array}$ & $\begin{array}{l}97 \% \text { dos pacientes } \\
\text { apresentaram sintomas } \\
\text { compatíveis coma a } \\
\text { infecção por vírus Zika } \\
\text { antes do início da } \\
\text { síndrome de Guillain- } \\
\text { Barré. Para o vírus Zika } \\
\text { por RT-PCR*, os } \\
\text { resultados foram } \\
\text { positivos em 40\% dos } \\
\text { pacientes. }\end{array}$ & $\begin{array}{l}\text { A evidência da infecção pelo } \\
\text { vírus Zika documentada por } \\
\text { RT-PCR* entre pacientes } \\
\text { com síndrome de Guillain- } \\
\text { Barré durante o surto da } \\
\text { infecção na Colômbia presta } \\
\text { apoio ao papel no } \\
\text { desenvolvimento da } \\
\text { síndrome. }\end{array}$ \\
\hline
\end{tabular}


Outros estudos também apresentam em seus achados a indicação de que o Zika vírus atravessa a placenta e provoca a microcefalia. E com foco nas células progenitoras corticais, induz a morte celular por apoptose e prejudica o desenvolvimento neurológico ${ }^{12}$.Com a infecção da mãe com o Zika vírus durante o primeiro trimestre de gravidez, estima-se que o risco de microcefalia é aproximadamente de $1 \%$. Apesar de parecer um baixo risco, se comparado com outras infecções virais, este traz uma importante diferença: sua incidência na população em geral pode ser muito alta durante os surtos (chegando a 66\% na Polinésia Francesa e $73 \%$ na Ilha Yap) ${ }^{9}$.

No que tange aos pacientes acometidos pela síndrome de Guillain-Barré, durante o surto do Zika vírus na Polinésia Francesa, estudos relatam que, em todos os casos, os sintomas da síndrome foram precedidos por sintomas de infecção por Zika, contando com erupção cutânea, artralgia, febre e hiperemia conjuntival. Os indivíduos acometidos pelo Zika vírus apresentam entre os principais sintomas: febre, erupção cutânea, cefaleia, mialgia, conjuntivite e artralgia, com uma média de quatro dias de duração ${ }^{13-14}$.

Ainda durante o surto na Polinésia Francesa, foram registrados um total de 42 casos da síndrome de GuillainBarré, sendo estimado em 0,24 para cada 1000 infecções por Zika vírus. As investigações sorológicas realizadas nas amostras de sangue dos 42 pacientes que desenvolveram síndrome de Guillain-Barré, durante o surto, confirmaram que todos eles haviam sido infectados pelo Zika vírus ${ }^{3}$. Também foi documentado um considerável aumento da incidência da síndrome de Guillain-Barré logo após a introdução do Zika vírus na Colômbia e a epidemia, se comparada com a ocorrida na Polinésia Francesa, mostra-se muito semelhante $\mathrm{e}^{14}$.

A grande preocupação acerca da infecção pelo vírus Zika relaciona-se ao seu potencial de fácil propagação, devido a ampla prevalência de seu vetor, ressaltando assim a necessidade de uma vigilância clínica, epidemiológica e laboratorial reforçada e de novas estratégias de controle de vetores, levando em consideração a ausência de uma terapia antiviral específica ou uma vacina para tratamento ou prevenção da infecção ${ }^{15-16}$.

Em 11 de novembro de 2015 o Ministério da Saúde declarou oficialmente uma situação de Emergência em Saúde Pública de Importância Nacional implicada pelo vírus $Z_{\text {Zika }}^{2}$. Tal fato ocorreu, pelo aumento exponencial no número de casos de microcefalia no nordeste do Brasil e a possibilidade de associação desses com a infecção pelo vírus, onde fez com que diversos pesquisadores retomassem seus estudos anteriores concernentes a Polinésia Francesa, por exemplo, a fim de descobrir dados que pudessem ter passado despercebidos, uma vez que teoricamente, o Zika não havia tido tamanha magnitude em outros países ${ }^{2-3,13,15}$.

Desde a ocorrência da primeira epidemia do vírus fora do solo africano, no ano de 2007, o número de publicações sobre o Zika chega ao máximo de quatro artigos em um ano. Entretanto, esses números crescem surpreendentemente desde 2014, atingindo o seu auge no ano de 2016, com 646 artigos publicados apenas no período de janeiro a junho ${ }^{2}$.

Desse grande número de artigos, muitos são no formato de opiniões e editoriais, e retratam a preocupação dos pesquisadores e da comunidade científica no geral, com o aumento do número de casos de infecção pelo Zika. Apesar do Zika vírus ser velho conhecido da comunidade científica, com relatos de casos em outros países há pelo menos 60 anos, transmitido pelo mesmo vetor do vírus da dengue, o Aedes aegypti, de comportamento benigno, baixíssima virulência e letalidade, pouco se conhecia sobre uma possível teratogenicidade ligada ao vírus Zika, o que passou a ser investigado nos casos brasileiros, e motivar as pesquisas científicas ${ }^{17}$

Nos sete estudos apresentados, observa-se nos resultados o cuidado dos pesquisadores em descrever as características da doença causada pelo Zika, além da sua relação com a microcefalia, apresentando evidências da transmissão vertical, das alterações observadas nos bebês, e da associação com a Síndrome de Guillain-Barré. Isso demonstra que antes da declaração de emergência em saúde pública de importância nacional, muito pouco conhecimento havia sobre esse tema, e com o incentivo financeiro e político do Ministério da Saúde e posteriormente em 2016, pela declaração de nível internacional pela Organização Mundial de Saúde, as descobertas foram sendo realizadas e ainda continuam nas buscas e confirmações sobre a doença $^{18}$.

Uma análise bibliométrica de publicações sobre o vírus Zika apresenta como temáticas abordadas com maior frequência, respectivamente, transmissão, surto, microcefalia e saúde do viajante. Porém, mesmo com o salto no número de publicações, diversos artigos ainda fazem menção a ausência de estudos experimentais, mesmo dentro destas temáticas mais abordadas, para efetivar métodos de prevenção e controle, por exemplo ${ }^{11,16,19-20}$.

\section{CONCLUSÃO}

Observa-se que a produção de artigos científicos após a declaração de emergência em saúde de importância nacional e, em seguida, internacional, resultou no desenvolvimento estável do interesse científico no vírus Zika e, consequentemente, em crescimento considerável no número de publicações com o tema, que até então era pouquíssimo estudado.

Ainda assim, há que se considerar um alto índice de artigos de opinião e estudos de caso nas bases de dados. Alguns usam como temática o direito reprodutivo e o aborto, por exemplo, mas não foi encontrado nenhum estudo que analise o impacto do Zika vírus e da microcefalia nas famílias afetadas, bem como estudos que deem voz a essas mães de crianças com microcefalia causada por vírus Zika, o que nos leva a indagar a ausência de estudos qualitativos em nossa busca.

Nota-se também que há uma centralidade nos esforços referentes ao controle epidemiológico e ambiental do surto de Zika no Brasil, em detrimento da análise da determinação social e condições sociais que envolvem a doença, visto ainda não haver publicação com foco na determinação social do surto de Zika vírus. Entretanto é inegável que muito tem sido feito para compreender o vírus e todas as suas implicações. No entanto, todos os artigos nos apontam a necessidade de mais estudos, de mais conhecimentos para que medidas de prevenção e controle possam ser tomadas.

Ainda há muitas perguntas sem respostas, entre elas cabe explicitar: como tem se dado o atendimento e tratamento das crianças com Síndrome Congênita do Zika? Como é o cotidiano das famílias com criança com Síndrome Congênita do Zika? Responder a estas questões é condição sinequanon. Também é preciso financiamento e incentivo à comunidade científica para o desenvolvimento de novas ferramentas acessíveis, incluindo testes diagnósticos e vacina, bem como novas metodologias eficazes de controle 
e combate ao vetor.

O Zika vírus não é mais considerado pela Organização Mundial de Saúde (OMS) uma situação de Emergência de Saúde Pública de importância internacional, desde novembro de 2016, contudo, o surto ainda é um grande desafio de saúde pública que exigirá avanço da ciência e enfrentamento governamental contínuo com vistas a impedir a recorrência do surto de Zika vírus.

\section{REFERÊNCIAS}

1. Wikan N, Smith DR. Zika virus: history of a newly emerging arbovírus. Lancet Infect Dis. 2016; 16(7):e119-26.

2. Diniz D. Zika: do Sertão nordestino à ameaça global. Rio de Janeiro: Civilização Brasileira; 2016

3. Cao-Lormeau VM, Blake A, Mons S, Lastere S, Roche $\mathrm{C}$, Vanhomwegen $\mathbf{J}$ et al. Guillain-Barré Syndrome outbreak associated with Zika virus infection in French Polynesia: a case-control study. Lancet . 2016; 387(10027):1531-9.

4. Maricato E. As cidades, o mosquito e as reformas. Waterlat-Gobacity. 2016; 3(9):30-7

5. Santiago PR. Desigualdade estrutural e microcefalia: o saneamento como direito negado. Waterlat-Gobacity. 2016; 3(9):38-43

6. Marinho F, Araújo VEM, Porto DL, Ferreira HL, Coelho MRS, Lecca RCR et al. Microcephaly in Brazil: prevalence and characterization of cases from the Information System on Live Births (Sinasc), 2000-2015. Epidemiol Serv Saúde. 2016; 25(4):701-12.

7. World Health Organization. Psychosocial support for pregnant women and for families with microcephaly and other neurological complications in the context of Zika virus: interim guidance for health-care providers. Genebra: WHO. 2016.

8. Mendes KDS, Silveira RCCP, Galvão CM. Integrative literature review: a research method to incorporate evidence in health care and nursing. Texto Contexto Enferm. 2008; 17(4):758-64.

9. Cauchemez S, Besnard M, Bompard P, Dub T, Guillemette-Artur P, Eyrolle-Guignot $\mathrm{D}$ et al. Association between Zika virus and microcephaly in French Polynesia, 2013-15: a retrospective study. Lancet. 2016; 387(10033):2125-32.

10. Ventura CV, Maia M, Ventura BV, Linden VVD, Araújo EB, Ramos RC et al. Ophthalmological findings in infants with microcephaly and presumable intrauterus Zika virus infection. Arq Bras Oftalmol. 2016; 79(1):1-3.

11. Mlakar J, Korva M, Tul N, Popovic M, Poljsak-Prijatelj M, Mraz J et al. Zika virus associated with microcephaly. N Engl J Med. 2016; 374(10):951-8.

12. Cugola FR, Fernandes IR, Russo FB, Freitas BC, Dias JLM, Guimarães KP et al. The Brazilian Zika virus strain causes birth defects in experimental models. Nature. 2016; 534(7606):267-71.

13. Watrin L, Ghawché F, Larre P, Neau JP, Mathis S, Fournier E. Guillain-Barré Syndrome (42 cases) occurring during a Zika virus outbreak in French Polynesia. Medicine. 2016; 95(14):e3257.

14. Parra B, Lizarazo J, Jiménez-Arango JA, Zea-Vera AF, González-Manrique G, Vargas J et al. Guillain-Barré Syndrome associated with Zika virus infection in Colombia. N Engl J Med. 2016; 375(16):1513-23.
15. Duffy MR, Chen TH, Hancock WT, Powers AM, Kool JL, Lanciotti RS et al. Zika virus outbreak on Yap Island, Federated States of Micronesia. N Engl J Med. 2016; 360(24): 2536-43.

16. Aggarwal R, Aggarwal H, Basu M, Chugh P. Zika virus disease. Int J Community Med Public Health. 2016; 3(6):1352-4

17. World Health Organization. Zika virus research agenda: october 2016. Genebra: WHO. 2016.

18. World Health Organization, Statement on the first meeting of the International Health Regulations (2005) (IHR 2005). Emergency Committee on Zika virus and observed increase in neurological disorders and neonatal malformations. Geneva. 2016.

19. Martins MFM. Bibliometric analysis of scientific articles on the Zika virus. RECIIS. 2016; 10(1):1-9.

20. Gatherer D, Kohl A. Zika virus: a previously slow pandemic spreads rapidly through the Americas. J Gen Virol. 2016; 97(2):269-73.

\section{CONFLITO DE INTERESSES}

Os autores declaram não haver conflitos de interesse.

\section{AUTOR PARA CORRESPONDÊNCIA}

Gabriella Barreto Soares

gabriella.barreto@yahoo.com.br

Submetido em 17/12/2017

Aceito em 17/01/2018 